de Jimena Fernández de la Vega y Käte Pariser, científicas dedicadas al campo de la genética. Fernández de la Vega, pensionada por la JAE y una de las primeras españolas en doctorarse en Medicina (1919), realizó estancias en Alemania y Austria que le permitieron profundizar en sus conocimientos sobre herencia y fisiología del desarrollo. Por su parte, la doctora Käte Pariser llegó a Madrid en 1933 con una beca para investigar sobre la herencia biológica del sexo y la aparición de individuos intersexuados. Con este viaje la judía Pariser perseguía un doble propósito: estimular su férreo deseo de proseguir con su formación científica y evitar el terrible ambiente hostil que se respiraba en Alemania tras la llegada del nazismo al poder. Sin embargo, ambas científicas vieron truncadas sus carreras por la situación política de la época. Este panorama completo del escenario político e intercultural germanoespañol de principios del siglo XX supone un marco redondo para que el lector se sumerja en el abanico de las historias de españolas que marcharon a Alemania becadas por la JAE. Así, Isabel Pérez-Villanueva Tobar muestra el importante papel que desempeñó la estancia en Marburgo en la carrera de la humanista y pedagoga María de Maeztu.
La contribución de Santiago López-Ríos y Arno Gimber es un reflejo de la fructífera estancia en Berlín de Juana Moreno de Sosa, discípula de Maeztu que estableció contacto con el escritor Thomas Mann durante su estancia en la capital alemana. Gracias a ello, Juana Moreno tradujo al español la obra Königliche Hoheit, el segundo libro de Thomas Mann que se publicó en España. Blanca Calvo y Ramón Salaberria nos acercan a otra de las Señoritas en Berlín: Teresa Andrés Zamora. Esta bibliotecaria y posterior militante comunista realizó una estancia en diferentes museos berlineses que le permitió configurar la política bibliotecaria de una España sumida en la Guerra Civil. Por su parte, Dieter Ingenschay recoge la huella berlinesa en las obras de las escritoras Rosa Chacel y María Teresa León, mujeres comprometidas con la situación política que les tocó vivir y víctimas del exilio tras la derrota republicana en España. Cuatro músicas y pedagogas musicales españolas (María García Arangoa, Pura Lago Couceiro, Josefa y Elisa Uriz Pi), que completaron su formación en distintas instituciones alemanas gracias a las becas de la JAE, son el objeto de estudio de Anna Teresa Macías García. Finalmente, el círculo de señoritas españolas lo cierra Carolina Rodríguez-
López, quien destaca el papel de la Sección Femenina de la Falange como organismo interesado en los nuevos conceptos de organización nacidos del ideario nacionalsocialista de Alemania. A este respecto destaca el Auxilio de Invierno -inspirado en el Winterhilfe nazi- que, entre otros cometidos, tenía el de socorrer a los hijos menores de fusilados, crear comedores y centros de maternidad, así como fundar hogares infantiles. La otra cara de este volumen lo forman las Fräulein que decidieron poner rumbo a su vida y marcharse a España, si bien la situación política en Europa obligaría a que esta estancia fuera temporal. De entre ellas, Gabriele Beck-Busse rescata a Leonie Feiler Sachs, doctora en Romanística, de cuyo hijo se incluyen además unas palabras de agradecimiento a la memoria de su madre. Mercedes del Amo recupera a dos víctimas judías del franquismo y del nazismo alemán: Gerda Leimdörfer, esposa de Salvador Vila rector de la Universidad de Granada que fue fusilado en 1936-, y su amiga Gretel Adler, quien también compartió el mismo destino trágico. Con su última contribución, Michael Scholz-Hänsel realiza un particular homenaje a la fotógrafa Gerda Taro. Acompañada de su marido Robert Capa, Taro llevó a cabo una notable labor de documentación fotográfica de las acciones del bando republicano durante la Guerra Civil española.

Pese a la aparente disparidad de procedencias, intereses y creencias, la vida de todas estas mujeres estuvo hilvanada por el mismo hilo conductor y convulsivo del periodo europeo de entreguerras. La valiente actitud de estas mujeres y su amor por el trabajo constituyen un ejemplo de la importancia de las relaciones interculturales estables en la formación humana. Precisamente esta idea pone de manifiesto el enorme valor de este magnífico volumen, que recupera el recuerdo común de un pasado no tan lejano

María González de León

\section{(20) \\ Deppermann, Arnulf (2008): \\ Gespräche analysieren. Eine Einführung.}

Wiesbaden: Springer VS, 2008 (4a edición).

http://dx.doi.org/10.12795/ mAGAzin.2015.i23.11

Las conversaciones son situaciones de comunicación en las que interactúan dos o más personas, siguiendo unos turnos de palabras organizados, y en las que se refleja la subjetividad 
e individualidad de cada hablante. La complejidad de estas interacciones y el creciente interés en los últimos años por el estudio de la Pragmática han propiciado numerosas investigaciones, como esta de Deppermann, sobre métodos de análisis empíricos cualitativos del análisis de la conversación.

Gespräche analysieren, publicado por primera vez en 1999 y reeditado en 2008, presenta los principios metodológicos y los procedimientos necesarios para un correcto análisis conversacional, y sirve de gran ayuda para los aprendices que se inician en el estudio de este campo. El manual hace un breve recorrido de esta disciplina surgida en 1968 en el campo de la sociología de la mano de H. Sacks. Sin embargo, el investigador más conocido en el campo de la interacción lingüística es E. A. Schegloff, alumno de Sacks. Hoy en día el análisis conversacional constituye un campo autónomo de investigación, centrado en el estudio de cómo usan y organizan los hablantes de una lengua la comunicación oral para que se pueda llevar a cabo una interacción verbal $y$, por consiguiente, las acciones sociales.

La obra está dividida en siete capítulos, caracterizados, a excepción del primero, por una breve anotación introductoria sobre qué aspectos aborda cada uno de ellos. Asimismo, algunos de los apartados constan de una breve check list final de gran ayuda a la hora de realizar un análisis conversacional. A mi parecer, esta conforma cuestiones claves que sirven de resumen para comprobar que el lector ha entendido lo expuesto en el contenido de esa sección.

Desde el primer capítulo ya se destacan las características generales que se pueden observar en una conversación, pues se parte de que esta se produce de forma intencionada por los hablantes y de que se organiza siguiendo un patrón de actividades en un espacio temporal. De igual forma, para evitar que la conversación se convierta en un monólogo, se hace hincapié en la necesidad de que los participantes en dicha conversación interactúen mutuamente, ya que, como se ha comentado anteriormente, una buena interacción se produce con dos o más hablantes, a la vez que se persiguen unos objetivos comunes e individuales. Por otro lado, Deppemann también hace mención de la importancia de una gegenstandsfundierte Methodik, es decir, de una "metodología fundamentada en el objeto de estudio". Durante todo su trabajo se pone de manifiesto el rechazo a cualquier hipótesis y metodología que se realice a priori.

Según los intereses del investigador se optará por

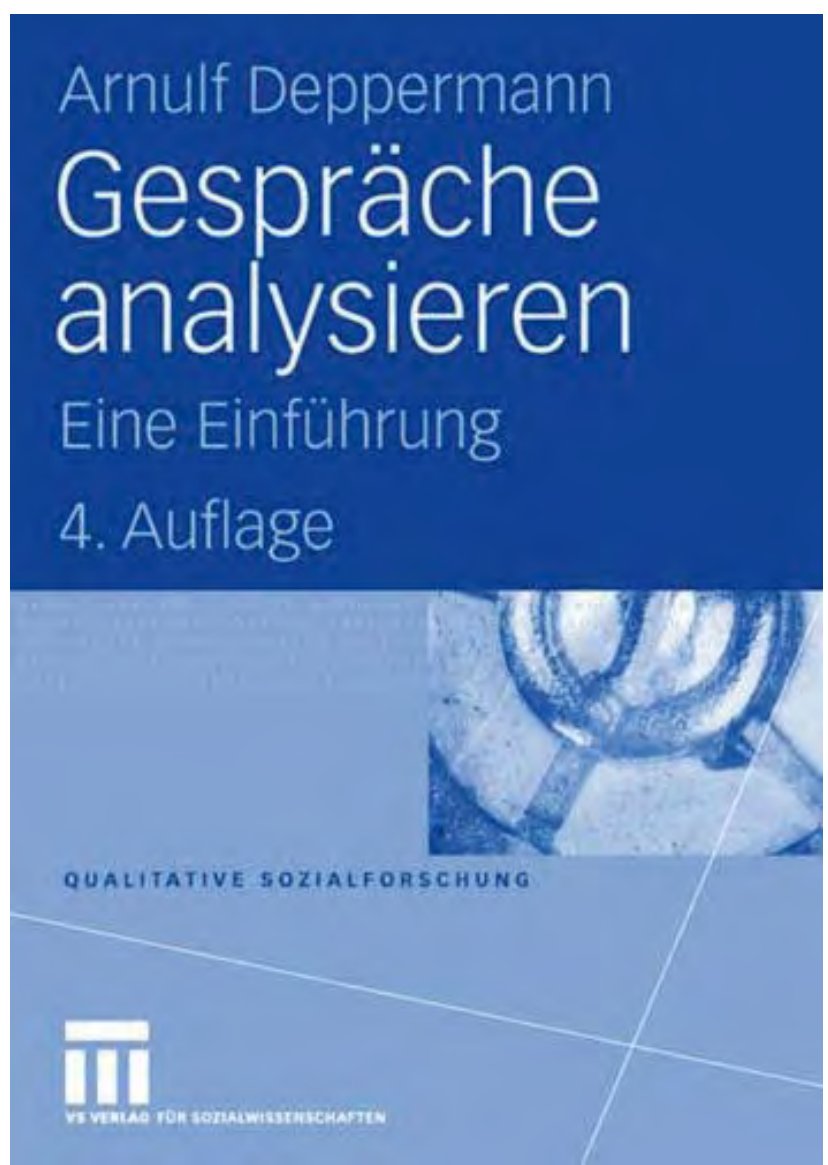

una metodología u otra. Para sentar las bases de dicha metodología es necesario fijar unos planteamientos de problemas, ya que éstos determinarán al final qué datos serán indispensables para la elaboración del material y qué fenómenos se reproducirán en el transcrito. De esta manera, dentro de los planteamientos del análisis se producen una serie de diferencias y semejanzas que se abordan de forma general en el apartado dos de este libro.

Otros aspectos significativos en la investigación son los referentes a las técnicas de grabación y las actividades de recopilación: la importancia del tono y el vídeo, los criterios que hay que seguir para obtener una buena grabación como por ejemplo, la importancia de una reproducción fiel del material, qué técnicas hay que tener en cuenta $u$ otros datos relevantes para el análisis (estados de ánimos, impresiones, edad, etc.).

Una vez recopilados los datos se pasará a la elaboración del material. Para ello, Deppermann indica los cuatro pasos principales que se deben seguir en dicha elaboración: la creación de un inventario, la fijación de las metas de investigación, la selección de los pasajes oportunos que se analizarán 
y por último, la realización de la correspondiente transcripción. Otro aspecto que hay que tener en cuenta es la presencia de datos sobre los participantes: es necesario sustituir los nombres propios, los lugares o algún otro dato relevante de la conversación; Deppermann aconseja incluso usar seudónimos, o como él llama Maskierungsschlüssel.

La transcripción desempeña un papel fundamental $y$ necesario en el análisis de la conversación. La transcripción debe reflejar, de la manera más fiel posible, lo expresado por los participantes de la conversación de modo que recoja cualquier dato relevante para posteriores análisis. La elaboración se lleva a cabo siguiendo unas normas de transcripción; en este caso Deppermann recomienda seguir las normas del sistema de transcripción elaboradas por Selting (GAT-2).

El capítulo central del libro (el seis), y a la vez el más extenso, aborda el tema del análisis de la conversación en sí. Importante aquí son los procedimientos y los principios que siguen los hablantes en la conversación, cómo se ordenan en ella y qué significado tienen. Asimismo, las cuestiones de cómo comenzar con el análisis y qué pasajes de la conversación seleccionar para realizar el estudio detallado forman, junto a los objetivos, el corazón de la investigación. No obstante, es fundamental preguntarse durante el análisis no solo el "cómo" y el "para qué", sino también el "por qué" de cada unidad sintáctica. Por otro lado, para el buen entendimiento y una correcta interpretación del análisis de la conversación, hay que tener en cuenta los conocimientos previos de los que disponen los hablantes y el investigador. Éste tiene que tener además unos conocimientos teóricos $\mathrm{y}$ etnográficos.

Finalmente, el libro concluye con la formulación de unos criterios científicos de calidad aplicables al análisis conversacional, como son Reliabilität -precisión y fiabilidad de los datos- y Validität -la relación de los datos con la realidad social y los conceptos teóricos, verdad $y$ generalidad de los enunciados-. Además, Deppermann señala la necesidad de "transparencia en el proceso de investigación", de "relevancia” y de "originalidad". Todas ellas, junto con el principio de naturalidad típico del lenguaje oral, constituyen los factores primordiales para la investigación.

En definitiva, Gespräche analysieren ofrece al lector una visión completa $\mathrm{y}$ precisa sobre el análisis conversacional. No obstante, se echan en falta aspectos que, a mi juicio, son de especial interés para los lectores, como la falta de ejemplos concretos o la sugerencia de programas específicos para la elaboración de los corpora, por ejemplo.

Rosa Ma Morales Vázquez

\section{Bereit für eine Entdeckungsreise?}

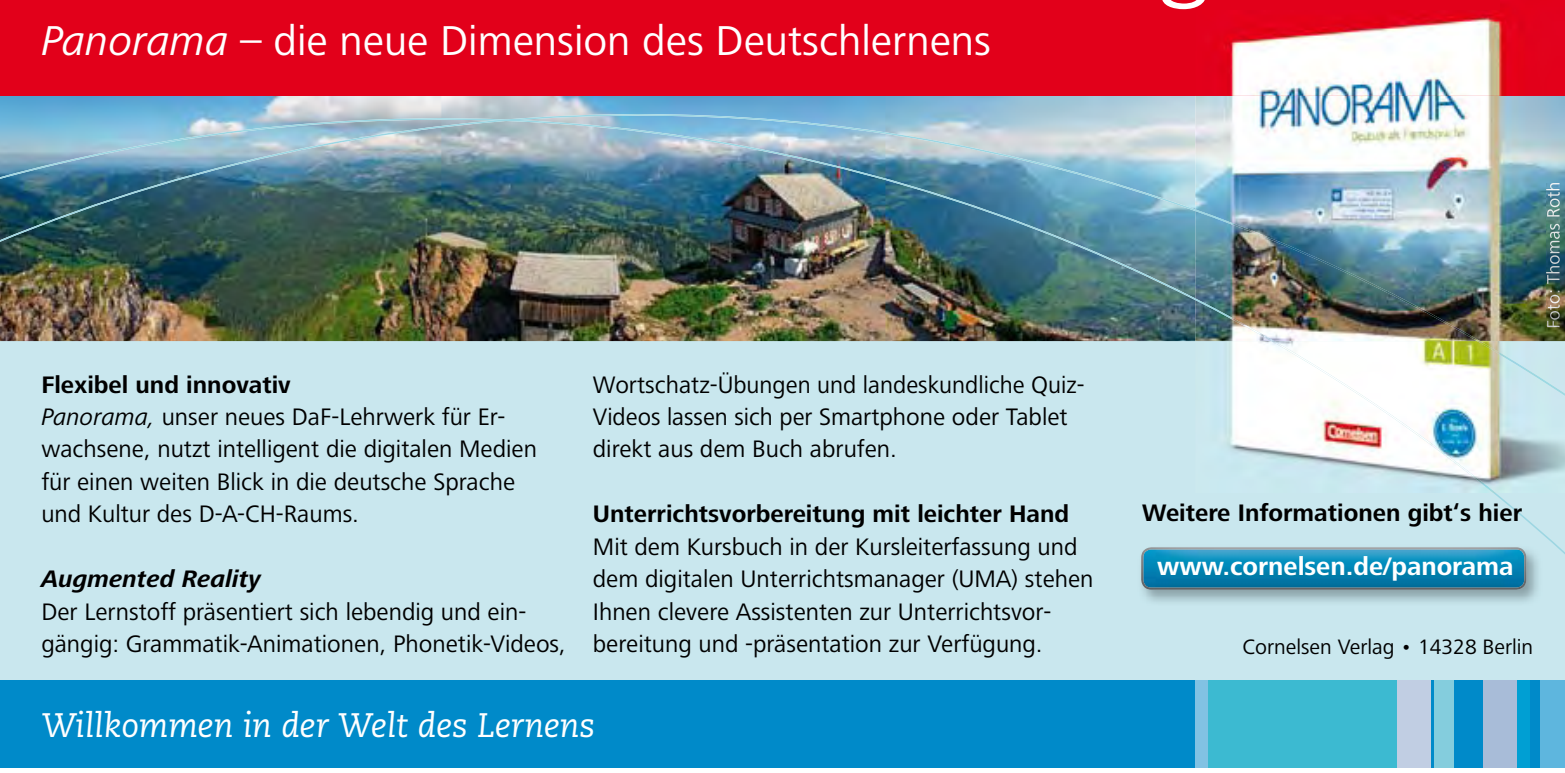

